\title{
Transcatheter closure of small ductus arteriosus with amplatzer vascular plug
}

\author{
Eun Hyun Cho, MD', Jinyoung Song, MD, PhD', I-Seok Kang, MD'1 June Huh, MD, PhD', Sang Yoon Lee, MD², Eun Young Choi, MD³, \\ Soo Jin Kim, MD, PhD \\ ${ }^{1}$ Department of Pediatrics, Samsung Medical Center, Sungkyunkwan University School of Medicine, Seoul, ${ }^{2}$ Department of Pediatrics, Sejong General Hospital, \\ Bucheon, ${ }^{3}$ Department of Pediatrics, Seoul National University Bundang Hospital, Seongnam, ${ }^{4}$ Department of Pediatrics, Konkuk University Medical Center, Seoul, \\ Korea
}

Purpose: The purpose of this study was to share our experience of transcatheter closure of small patent ductus arteriosus (PDA) by using an Amplatzer vascular plug (AVP).

Methods: We reviewed the medical records of 20 patients who underwent transcatheter closure at Samsung Medical Center and Sejong General Hospital from January 2008 to August 2012. The size and shape of the PDAs were evaluated by performing angiograms, and the PDA size and the AVP devices size were compared.

Results: The mean age of the patients was $54.9 \pm 45.7$ months old. The PDAs were of type $C(n=5)$, type $D(n=12)$, and type $E(n=3)$. The mean pulmonary end diameter of the PDA was $1.7 \pm 0.6 \mathrm{~mm}$, and the aortic end diameter was $3.6 \pm 1.4 \mathrm{~mm}$. The mean length was $7.3 \pm 1.8 \mathrm{~mm}$. We used 3 types of AVP devices: AVP I ( $n=5)$, AVP $\|(n=7)$, and AVP IV $(n=8)$. The ratio of AVP size to the pulmonary end diameter was $3.37 \pm 1.64$, and AVP size/aortic end ratio was $1.72 \pm 0.97$. The aortic end diameter was significantly larger in those cases repaired with AVP II than in the others $(P=0.002)$. The AVP size did not significantly correlate with the PDA size, but did correlate with smaller ratio of AVP size to aortic end diameter $(1.10 \pm 0.31, P=0.032)$.

Conclusion: Transcatheter closure of small PDA with AVP devices yielded satisfactory outcome. AVP II was equally effective with smaller size of device, compared to others.

Key words: Patent ductus arteriosus, Cardiac catheterization, Vascular access devices

\section{Introduction}

It has been more than four decades since transcatheter closure of patent ductus arteriosus (PDA) was introduced ${ }^{11}$. Occlusion devices and transcatheter closure techniques have developed rapidly, and excellent outcomes and low complication rates are the standard $^{2-5}$. Therefore, transcatheter closure is the preferred treatment method for most PDA. Nowadays, Amplatzer ductal occluder (AD0) is the most widely used device for PDA closure, and the coil is effective for small PDA. However, the closure of a small asymptomatic PDA that is hemodynamically stable is controversial. Nonetheless transcatheter closure of PDA is technically easy and safe and even in small ductus, infective endocarditis is a concern in untreated cases ${ }^{6-12}$. Therefore, the transcatheter closure of PDA, regardless of the ductus size, is recommended. Transcatheter closure of a small PDA might be technically challenging from the antegrade approach, and the type of PDA is important for device selection. The purpose of this study was to share our experiences of transcatheter closure of small PDA using Amplatzer vascular plug (AVP;
Corresponding author: Jinyoung Song, MD, PhD Department of Pediatrics, Samsung Medical Center, Sungkyunkwan University School of Medicine, 81 Irwon-ro, Gangnam-gu, Seoul 135-710, Korea Tel: +82-2-3410-3538, Fax: +82-2-3410-0043, E-mail: amyjys@naver.com

Received: 26 June, 2013 Revised: 24 July, 2013 Accepted: 5 August, 2013
Copyright ( $\odot 2013$ by The Korean Pediatric Society

This is an open-access article distributed under the terms of the Creative Commons Attribution NonCommercial License (http://creativecommons.org/ licenses/by-nc/3.0/ which permits unrestricted noncommercial use, distribution, and reproduction in any medium, provided the original work is properly cited. 
AGA Medical Co., Golden Valley, MN, USA).

\section{Materials and methods}

We retrospectively reviewed the medical records of 20 pediatric patients who underwent transcatheter PDA closure at Samsung Medical Center and Sejong General Hospital from January 2008 to August 2012. The indications for PDA closure were evidence of shunt flow by echocardiogram, regardless of PDA size or symptoms, and no evidence of irreversible pulmonary hypertension due to left to right shunt. Our indications for using AVP for transcatheter closure of PDA were as follows: 1) relatively short ampulla of PDA or tubular shaped, Krichenko type (C, D or E) PDA ${ }^{13)}$, 2) too small pulmonary end for catheter passing, 3) tortuous PDA, or 4) when coil for PDA was not available.

The PDA was confirmed by echocardiogram after clinical examination of significant or innocent cardiac murmur. Postprocedural echocardiogram was repeated on the day after catheterization, and again 6 months afterwards. The research protocol was approved by the Institutional Review Boards of respective institutions.

\section{Procedure}

The transcatheter procedure was the same for all patients. However, size selection and technique for implantation were different due to different types of AVP and different operators.

Cardiac catheterization was performed under local anesthesia or moderate-to-deep sedation. After the aortic arch angiography, PDA size was measured at pulmonic communication, aortic communication, largest diameter at the middle of ductus, and PDA length. Heparin was injected just one time immediately after the puncture of femoral artery. Selection of AVP was dependent on operators and availability of AVP type on the date of procedure.

AVP I was used prior to AVP II or AVP IV became available in Korea. The implantation of AVP I was performed by a retrograde approach. PDA size was measured on aortogram, and PDA was selected by curved end-hole catheter. If the wire could not pass the pulmonary end due to constriction, AVP I was chosen. The catheter was positioned inside the tubular portion of PDA. The size of AVP I was 1-4 mm larger than the largest diameter of tubular portion in PDA. AVP I was deployed inside of PDA.

AVP II implantation was performed by an anterograde approach. A floppy-tipped wire traversed the PDA from pulmonary artery to descending aorta, and the delivery catheter was passed over the wire. AVP II with diameter 2-4 mm larger than that of PDA was selected. The first segment or distal retention disc of AVP II was deployed in the descending aorta, and the devices were pulled back for anchoring compactly in aortic ampulla. The main body of AVP II was deployed inside of PDA, and the proximal disc was deployed after passing the pulmonic end.

AVP IV was selected in cases of small tubular PDA in which 4 French curved catheter was passed by retrograde approach. The implantation was performed with 2-4 mm larger size of AVP IV. The first segment of AVP IV was deployed in the pulmonary artery, and the device was pulled back for anchoring compactly in the distal pulmonary end. The proximal segment of AVP IV was deployed within the ductus.

Upon delivery, the stability of device was tested by pulling and pushing gently on the delivery cable. Implantation stability and residual leak was evaluated on angiography.

\section{Statistics}

Values are reported as mean \pm standard deviation and ranges. We used a nonparametric test, Kruskal-Wallis test for three or more variables, and Mann-Whitney $U$ test for two independent variables to determine associations of AVP with various factors such as age, body weight, PDA size, and PDA/AVP ratio. Simple correlation analysis was performed for nonparametric methods between AVP and PDA size. A chi-square test was used for discrete variables. IBM SPSS ver. 19.0 (IBM Co., Armonk, NY, USA) was used for analysis. Null hypotheses of no difference were rejected if $P$ values were less than 0.05 .

Table 1. Clinical characteristics of the patients $(n=20)$

\begin{tabular}{lc}
\hline Characteristic & Value \\
\hline Age (mo) & $54.9 \pm 45.7(9-199)$ \\
Gender (male/female) & $8(40) / 12(60)$ \\
Body weight (kg) & $18.7 \pm 11.3(9-60)$ \\
Murmur (+) & $9(45)$ \\
PDA type & \\
C & $5(25)$ \\
D & $12(60)$ \\
E & $3(15)$ \\
PDA diameter (mm) & \\
Pulmonary end & $1.7 \pm 0.6(1.0-3.2)$ \\
Middle & $2.3 \pm 0.9(0.9-4.3)$ \\
Aortic end & $3.6 \pm 1.4(1.2-6.0)$ \\
PDA length (mm) & $7.3 \pm 1.8(4.3-12.0)$ \\
AVP/PDA size ratio & \\
AVP/pulmonary end & $3.4 \pm 1.6(1.7-8.0)$ \\
AVP/middle of PDA & $2.8 \pm 1.6(1.3-7.3)$ \\
AVP/Aortic end & $1.7 \pm 1.0(0.7-5.0)$ \\
\hline
\end{tabular}

Values are presented as mean \pm standard deviation (range) or number (\%). PDA, patent ductus arteriosus; AVP, Amplatzer vascular plug. 


\section{Results}

\section{Characteristics of the patients and AVP}

The mean age at catheterization was 54.9 \pm 45.7 months (range, 9 to 199 months), and mean body weight was $18.7 \pm 11.3 \mathrm{~kg}$ (range, 9 to $60 \mathrm{~kg}$ ). A murmur was audible in 9 patients, 45\% of all patients (Table 1), but no patient had clinical symptoms from PDA.

Ductal morphology was classified by Krichenko types ${ }^{10)}$ : type C ( $n=5,25 \%)$, type $D(n=12,60 \%)$, and type $E(n=3,15 \%)$. The mean diameter was $1.7 \pm 0.6 \mathrm{~mm}(1.0$ to $3.2 \mathrm{~mm}$ ) at pulmonary end, $2.3 \pm 0.9 \mathrm{~mm}$ (0.9 to $4.3 \mathrm{~mm}$ ) at the middle of ductus, and was $3.6 \pm 1.4 \mathrm{~mm}$ (1.2 to $6.0 \mathrm{~mm}$ ) at aortic end. Mean length of PDA was $7.3 \pm 1.8 \mathrm{~mm}$ (4.3 to $12.0 \mathrm{~mm}$ ). All PDAs were tubular (Krichenko types C, D, and E), and the sizes of aortic end were less than twice of the size of pulmonary end. The shunt amount was not checked because the PDA was small in all angiogram.

Three types of AVP were used: AVP I ( $n=5,25 \%)$, AVP II
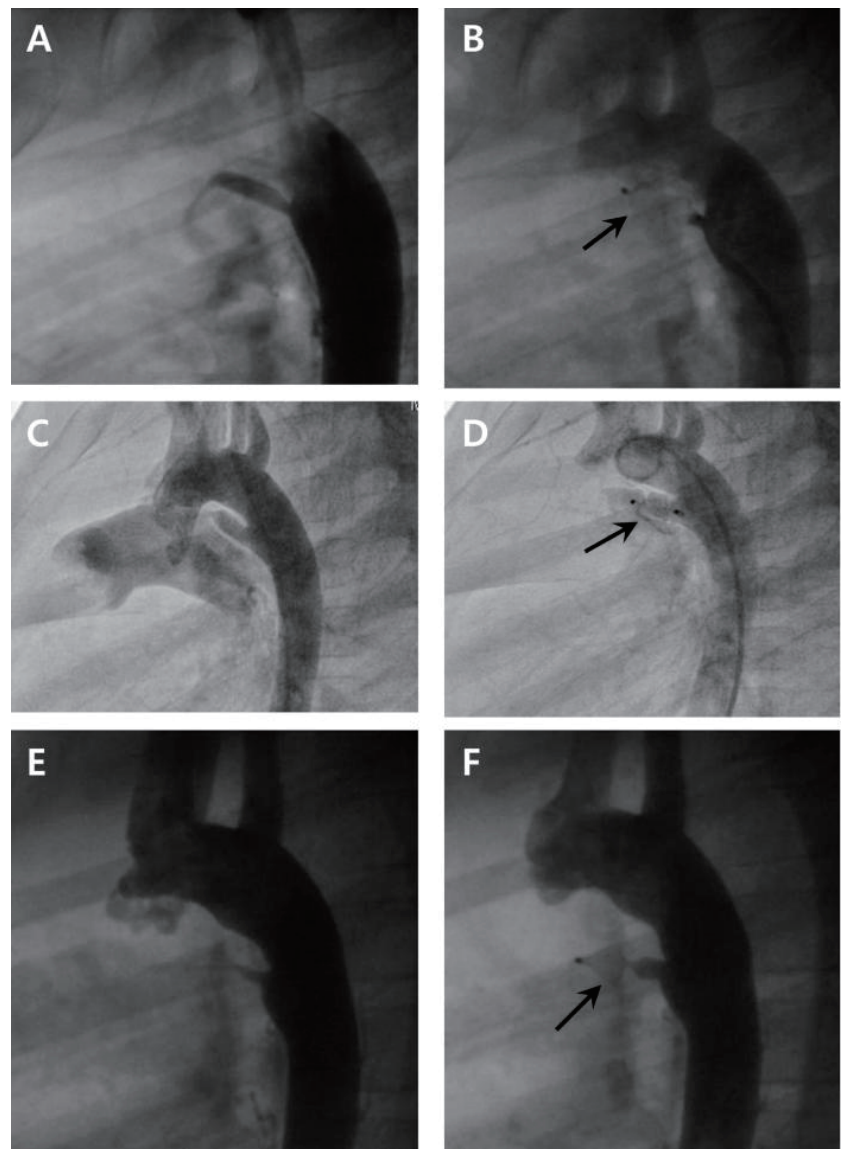

Fig. 1. Angiographies before and after implantation of Amplatzer vascular plug I (A, B), II (C, D), and IV (E, F): Long tubular type of patent ductus arteriosus and constriction of pulmonic end were visualized. Vascular plugs (arrows) were implanted successfully and complete closure was achieved.
( $n=7,35 \%)$, AVP IV (n=8, 40\%) (Fig.1). There was no significant relation between Krichenko type and AVP type used $(P>0.05)$. AVP size ranged between $4 \mathrm{~mm}$ to $8 \mathrm{~mm}$, and the mostfrequently used size was $4 \mathrm{~mm}$ in 10 patients (50\%).

The ratios of AVP size to PDA size were $3.37 \pm 1.64$ (1.67 to 8.00) for AVP/pulmonary end, $2.77 \pm 1.60$ (1.33 to 7.27) for AVP/middle of PDA, and $1.72 \pm 0.97$ (0.67 to 5.00) for AVP/aortic end.

\section{Correlations of AVP sizes with PDA sizes}

There were no significant differences in PDA size, pulmonary end, the middle portion, and length across the types of AVP, but AVP types varied significantly according to aortic end diameter of PDA ( $P=0.002)$ (Table 2). Further analysis revealed that the aortic end of a PDA was significantly larger for cases with AVP II, when compared with others AVP types, resulting in a more conical shaped PDA. The ratios of AVP size to the PDA size showed no difference according to types of AVP, except that AVP size/aortic end size in the case of AVP II was smaller than others $(P=0.032)$. There were no significant differences in age and body weight across the AVP types (Table 2).

The size of AVP had no significant correlation with PDA size including pulmonary end diameter, diameter at the middle of ductus, aortic end diameter, and the length $(P>0.05)$ (Table 3$)$.

Table 2. Associations of age, body weight, fluoroscopic time, PDA size, PDA/AVP ratio with plug type

\begin{tabular}{lllll}
\hline Variable & AVP I $(\mathrm{n}=5)$ & AVP $\|(\mathrm{n}=7)$ & AVP IV $(\mathrm{n}=8)$ & $P$ value \\
\hline Age $(\mathrm{mo})$ & $38.0 \pm 20.1$ & $57.1 \pm 65.6$ & $63.0 \pm 38.5$ & 0.415 \\
Body weight $(\mathrm{kg})$ & $13.6 \pm 3.6$ & $21.8 \pm 17.5$ & $19.1 \pm 7.0$ & 0.298 \\
PDA size $(\mathrm{mm})$ & & & & \\
$\quad$ Pulmonary end & $1.7 \pm 0.5$ & $1.8 \pm 0.7$ & $1.7 \pm 0.7$ & 0.913 \\
$\quad$ Middle & $2.3 \pm 0.7$ & $2.5 \pm 1.0$ & $2.0 \pm 1.0$ & 0.553 \\
Aortic end & $2.5 \pm 0.8$ & $5.0 \pm 0.7$ & $3.0 \pm 1.1$ & 0.002 \\
Length & $7.7 \pm 1.6$ & $7.1 \pm 1.7$ & $7.3 \pm 2.3$ & 0.691 \\
AVP/PDA ratio & & & & \\
$\quad$ AVP/pulmonary & $2.88 \pm 1.22$ & $3.44 \pm 1.83$ & $3.62 \pm 1.83$ & 0.476 \\
AVP/middle & $2.20 \pm 1.38$ & $2.54 \pm 1.51$ & $3.34 \pm 1.80$ & 0.211 \\
AVP/aortic & $2.13 \pm 1.61$ & $1.10 \pm 0.31$ & $2.00 \pm 0.62$ & 0.032
\end{tabular}

Values are presented as mean \pm standard deviation.

PDA, patent ductus arteriosus; AVP, Amplatzer vascular plug.

Table 3. Correlation of AVP size with PDA size

\begin{tabular}{lcc}
\hline Size of AVP & $\begin{array}{c}\text { Correlation coefficient } \\
\text { (Spearman rho) }\end{array}$ & $P$ value \\
\hline Size of PDA & & \\
Pulmonary end & 0.031 & 0.897 \\
The middle & 0.089 & 0.708 \\
Aortic end & 0.229 & 0.332 \\
Length & 0.045 & 0.850
\end{tabular}

PDA, patent ductus arteriosus; AVP, Amplatzer vascular plug. 


\section{Procedural failure and complications}

Among the 20 cases, there were no perioperative complications to report, and device implantations were successful in all patients. Neither residual shunt nor complications such as left pulmonary artery obstruction or coarctation of aorta were noted on repeat echocardiography at 24 hours and at 6 months post procedure.

\section{Discussion}

PDA morphology is highly variable. Krichenko classified the shape of PDA into five different types, broadly ${ }^{13)}$. Depending on the size and shape of PDA, various types of devices have been used in transcatheter closure of PDA. For most children and adult with PDA, safe and effective transcatheter closure of PDA has been achieved with $\mathrm{ADO}^{2,5,14,15)}$. Also, varying sizes of PDA had been occluded with the use of single or multiple coils ${ }^{3,16}$. ADO II is a modification of the original ADO and was designed for improved occlusion and better positioning. However, ADO II was not available in South Korea at that moment. After various types of AVP have become available, a few cases of successful PDA closure using these devices, even in preterm neonates, have been reported ${ }^{5,15)}$.

In transcatheter closure of small PDA, it is difficult to pass the wire from pulmonary artery to descending aorta, and a snaring technique is useful for passing the wire through a PDA. In such cases, this technically challenge prolongs the procedural duration and increases the risk of complications. However, most AVPs allow occlusion of a PDA from a retrograde approach. An AVP IV device is very useful in small infants because it is possible to use 4 French normal catheters to deliver the device. Also, an AVP device could be much more efficacious than an ADO device in long tubular type PDAs. Most PDAs have a pulmonary end constriction, and a multi-segmented type AVP can be anchored easily. AVP I is not designed for anchoring but for packing into the tubular type PDA. As such, it does not protrude into the aorta or pulmonary artery after implantation. However, for AVP II or AVP IV, it is difficult to prevent the implanted devices from protruding into aorta or pulmonary artery. However, the protruding portion is only a small portion of the whole vessel, and ductal aneurysm is placed in the pulmonary artery or aorta. We believe that there is little risk of hemodynamic instability after PDA closure with AVP. In this retrospective review, none of the patients exhibited hemodynamic issues after the closure of PDA. In our study, AVP I device was used when neither AVP II nor AVP IV devices were available. Even though the indication for a specific device was not clear, AVP I was preferred for long tubular PDAs with very small pulmonic ends. An AVP II device was used when PDA appeared too small for ADO but too large for AVP IV device.

The choice of device size is more dependent on the overall anatomic features of the PDA: 1) areas of restriction along the length of PDA, 2) the presence and size of the ampulla on aortic end, 3) the length of PDA, and 4) the proximity to the left pulmonary artery. Because PDA is fairly compliant and stretchable, it could be safer to choose oversized device. In previous publications, the device to vessel size ratio for original AVP to tubular type PDA varies from $136 \%{ }^{17)}$ to $228 \%{ }^{18)}$. We chose oversized device by measuring the largest tubular portion of PDA. We also considered the length of PDA because a larger AVP is more likely to protrude into the aortic lumen. Therefore, an AVP of 1-2 mm larger than the largest diameter of the PDA was selected for a relatively short PDA, whereas an AVP of 2-4 $\mathrm{mm}$ larger was selected for a longer PDA. From our findings, the size of AVP can be considered less than $200 \%$ of the aortic end diameter and $250 \%$ of middle portion of small tubular PDA. In a report regarding the use of AVP II devices for two cases of PDA closure $^{15)}, 10-\mathrm{mm}$ AVP II was used for a PDA with a minimum diameter of $5.5 \mathrm{~mm}$ (180\% of the minimum PDA diameter), and in the second case, 8-mm AVP II was used in a PDA with a minimum diameter of $3.5 \mathrm{~mm}$ (230\% of the minimum PDA diameter)

Schneider and Moore ${ }^{19)}$ reviewed the indications for PDA closure and supported definite indications in certain patients, including those who are symptomatic with left-right shunt and those who are asymptomatic but have left heart enlargement. They recommended that, even though it was not clear if the closure of a small PDA was beneficial, routine closure of any PDA in children and young adults appeared reasonable ${ }^{19)}$. The reasons for this recommendation included the risk of infective endocarditis and low-or-zero morbidity from closure, especially when using a transcatheter device. Fortescue et al. ${ }^{7)}$ assumed that the annual risk of infective endocarditis associated with an untreated, asymptomatic PDA would be around $0.001 \%$ to $0.01 \%$, with approximately $0.1 \%$ of lifetime risk. After PDA closure, this risk for endocarditis decreases is reported to decrease to the risk levels experienced by the general population ${ }^{7,9,10)}$.

All of our patients have small PDAs with or without audible cardiac murmur. It was not necessary to check shunt amount because of the insignificant amount but no residual shunt was checked in any of the patients one day after procedure.

This study was retrospective, and the procedures were performed by many operators. For these reasons, we could not determine clear indications for types and sizes of AVP, according to the PDA size and shape. Nevertheless, we found that AVP was useful for closure of small, tubular type PDA. To our knowledge, this is the first report describing the experience of transcatheter closure of PDA with 3 types of AVP. In the future, well-designed prospective studies with long term follow-up are needed to 
identify clear criteria for determining device size.

We experienced very successful transcatheter closure of small PDA with AVP I, II and IV devices. AVP II might be preferred due to good results with smaller size of device, when compared to others.

\section{Conflict of interest}

No potential conflict of interest relevant to this article was reported.

\section{References}

1. Porstmann W, Wierny L, Warnke H, Gerstberger G, Romaniuk PA. Catheter closure of patent ductus arteriosus. 62 cases treated without thoracotomy. Radiol Clin North Am 1971;9:203-18.

2. Dimas VV, Takao C, Ing FF, Mattamal R, Nugent AW, Grifka RG, et al. Outcomes of transcatheter occlusion of patent ductus arteriosus in infants weighing $\leq 6 \mathrm{~kg}$. JACC Cardiovasc Interv 2010;3:1295-9.

3. Hijazi ZM, Lloyd TR, Beekman RH 3rd, Geggel RL. Transcatheter closure with single or multiple Gianturco coils of patent ductus arteriosus in infants weighing < or $=8 \mathrm{~kg}$ : retrograde versus antegrade approach. Am Heart J 1996;132:827-35.

4. Park YA, Kim NK, Park SJ, Yun BS, Choi JY, Sul JH. Clinical outcome of transcatheter closure of patent ductus arteriosus in small children weighing $10 \mathrm{~kg}$ or less. Korean J Pediatr 2010;53: 1012-7.

5. Prsa M, Ewert P. Transcatheter closure of a patent ductus arteriosus in a preterm infant with an Amplatzer Vascular Plug IV device. Catheter Cardiovasc Interv 2011;77:108-11.
6. Balzer DT, Spray TL, McMullin D, Cottingham W, Canter CE. Endarteritis associated with a clinically silent patent ductus arteriosus. Am Heart J 1993;125:1192-3.

7. Fortescue EB, Lock JE, Galvin T, McElhinney DB. To close or not to close: the very small patent ductus arteriosus. Congenit Heart Dis 2010;5:354-65.

8. Malnick SD, Shimoni S, Zimhony 0. An unusual case of endocarditis. CMAJ 2006;174:1087-8.

9. Onji K, Matsuura W. Pulmonary endarteritis and subsequent pulmonary embolism associated with clinically silent patent ductus arteriosus. Intern Med 2007;46:1663-7.

10. Ozkokeli M, Ates M, Uslu N, Akcar M. Pulmonary and aortic valve endocarditis in an adult patient with silent patent ductus arteriosus. Jpn Heart J 2004;45:1057-61.

11. Parthenakis FI, Kanakaraki MK, Vardas PE. Images in cardiology: silent patent ductus arteriosus endarteritis. Heart 2000;84:619.

12. Satoh T, Nishida N. Patent ductus arteriosus with infective endocarditis at age 92. Intern Med 2008;47:263-8.

13. Krichenko A, Benson LN, Burrows P, Moes CA, McLaughlin P, Freedom RM. Angiographic classification of the isolated, persistently patent ductus arteriosus and implications for percutaneous catheter occlusion. Am J Cardiol 1989;63:877-80.

14. Francis E, Singhi AK, Lakshmivenkateshaiah S, Kumar RK. Transcatheter occlusion of patent ductus arteriosus in pre-term infants. JACC Cardiovasc Interv 2010;3:550-5.

15. Ng B, Schneider DJ, Hokanson JS. Closure of tubular patent ductus arteriosus in infants and small children with the Amplatzer Vascular Plug II. Congenit Heart Dis 2011;6:64-9.

16. Ewert P. Challenges encountered during closure of patent ductus arteriosus. Pediatr Cardiol 2005;26:224-9.

17. Hoyer MH. Novel use of the Amplatzer plug for closure of a patent ductus arteriosus. Catheter Cardiovasc Interv 2005;65:577-80.

18. Cheatham JP. Not so fast with that Novel use: does AVP = PDA? Catheter Cardiovasc Interv 2005;65:581-3.

19. Schneider DJ, Moore JW. Patent ductus arteriosus. Circulation 2006;114:1873-82. 